\title{
DETERMINAN DEBT MATURITY STRUCTURE PERUSAHAAN CONSUMER GOODS YANG TERDAFTAR DI ISSI PERIODE 2012-2015
}

\author{
Gianissa Pandu Islamy \\ Mahasiswa Program Studi Ekonomi Islam-Fakultas Ekonomi dan Bisnis-Universitas \\ Airlangga \\ E-mail : Gianissa.pandu-13@feb.unair.ac.id \\ Nisful Laila \\ Departemen Ekonomi Syariah-Fakultas Ekonomi dan Bisnis-Universitas Airlangga \\ E-mail : nisul.laila@feb.unair.ac.id
}

\begin{abstract}
This research analyzes the influence of firm size, profitability, tangibility, and asset maturity variable to debt maturity structure of consumer goods company in Indonesia. The population of this study consists of companies of industrial goods and consumption listed in Indonesia Sharia Stock Index period 2012-2014. The sample was taken by using purposive sampling method so that obtained 19 companies that fulfill the requirement as a sample. The result of research with Fixed Effect estimation model shows that firm size, profitability, and asset maturity have significant effect to debt maturity structure with a different level of significance. Based on the value of the coefficient of determination $\left(R^{2}\right)$ of $92.06 \%$ shows that the percentage of the ability of exogenous variables in explaining endogenous variables of $92.06 \%$ while the rest of $7.94 \%$ explained by other variables outside this study.
\end{abstract}

Keywords: Debt Maturity Structure, Tangibility, Asset Maturity, ISSI.

\section{PENDAHULUAN}

Perkembangan pasar modal

syariah saat ini memiliki peran penting dalam peningkatan sistem finansial ekonomi berprinsip syariah di Indonesia. Dalam pasar modal terdapat ruang khusus untuk melakukan transaksi sesuai dengan syariat Islam yaitu ISSI. Indeks Saham Syariah Indonesia merupakan indeks saham yang mencerminkan keseluruhan saham syariah yang tercatat di BEl dan saham tersebut terdaftar dalam Daftar Efek Syariah.

Seiring berjalannya waktu perkembangan pasar modal syariah mengalami kemajuan. Kemajuan tersebut salah satunya ditandai dengan semakin banyaknya perusahaan yang mulai mendaftarkan sahamnya di lantai bursa.

Tabel 1.1 Daftar Pertumbuhan Kepesertaan
Perusahaan di ISSI

\begin{tabular}{|c|c|c|c|}
\hline No & Periode & $\begin{array}{c}\text { Ang } \\
\text { gota }\end{array}$ & $\begin{array}{c}\text { Prosentase } \\
\text { Pertumbuh } \\
\text { an (\%) }\end{array}$ \\
\hline 1 & 21 Mei 2011 & 220 & $0 \%$ \\
\hline 2 & 24 Mei 2012 & 286 & $30 \%$ \\
\hline 3 & 24 Mei 2013 & 293 & $2,4 \%$ \\
\hline 4 & 20 Mei 2014 & 306 & $4,4 \%$ \\
\hline 5 & 21 Mei 2015 & 317 & $3,5 \%$ \\
\hline \multicolumn{5}{c}{ Sumber: ojk.go.id } \\
Sumber kebutuhan dana bagi
\end{tabular}

perusahaan go public yang terdaftar dalam ISSI dapat diperoleh melalui sumber internal atau menggunakan sumber eksternal seperti menerbitkan surat berharga berupa utang yang disediakan oleh pihak-pihak di luar perusahaan dan modal saham.

Utang merupakan salah satu opsi yang dimiliki perusahaan dalam memenuhi kebutuhan perusahaan. Utang dalam islam tidaklah haram, namun dalam penggunaanya harus dibatasi dan 
Islamy, et al/Jurnal Ekonomi Syariah Teori dan Terapan Vol. 5 No. 7 Juli 2018: 556-573; DETERMINAN DEBT MATURITY DEBT MATURITY PERUSAHAAN CONSUMER GOODS YANG TERDAFTAR DI ISSI

tidak ada unsur bunga didalamnya.

Bunga yang dikenakan dalam transkasi utang piutang memasuki kriteria riba, di mana dalam prespektif Islam dilarang. Alquran dan Sunnah telah menjelaskan keharaman riba dengan berbagai bentuknya, Allah SWT berfirman dalam surah Al-Baqarah 275:

"Padahal Allah telah menghalalkan jual beli dan mengharamkan riba."

Perusahaan yang tergabung dalam ISSI harus memperhatikan proporsi antara pembiayaan berbasis utang dan berbasis ekuitas. Dalam aturan syariah di Indonesia yang direfleksikan melalui fatwa DSN NO. 20/DSN-MUI/IV/2001, telah diatur bahwa emiten saham yang dinyatakan syariah wajib memenuhi rasio-rasio kevangan seperti rasio total utang yang berbasis bunga dibandingkan dengan total asset tidak lebih dari $45 \%$. Artinya jika perusahaan ingin mendaftarkan saham syariahnya, perusahaan harus mampu mengelola rasio debt to assetnya. Di mana aset perusahaan maksimal hanya bisa didanai oleh utang sebesar $45 \%$. Dari aturan tersebut dapat ditarik kesimpulan bahwa penggunaan utang adalah boleh namun tetap harus dibatasi penggunaannya.

Menurut Barclay dan Smith (1995) ketika perusahaan memilih utang sebagai sumber pendaanan eksternal, maka perusahaan juga harus mempertimbangkan kebijakan financial yang lain, misalnya: Maturitas utang. Sukianto (2013:5) menyatakan bahwa maturitas utang merupakan batas waktu jatuh tempo perusahaan dalam melunasi sejumlah pinjaman atau dana kepada pihak kreditur. Struktur maturitas utang menjelaskan suatu komposisi utang berdasarkan jangka waktu yang dipergunakan oleh perusahaan, baik jangka panjang maupun jangka pendek dan dipengaruhi oleh besar kecilnya utang tersebut. Struktur maturitas utang dalam penelitian ini adalah presentase dari utang jangka panjang dibandingkan dengan total utang perusahaan. Hal ini didasarkan pada penelitian Barclay et al (1995). Semakin tinggi rasio ini maka semakin tinggi pula maturitas utangnya.

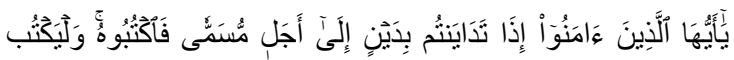

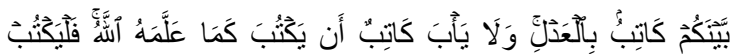

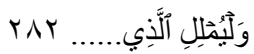

Yā ayyuhal-lażina āmañ̄ iżā tadāyantumbidaynin ila ajalim-musamman faktubüh. Walyaktub-baynakum kātibum-bil-'adl. Wa Iā ya'ba kātibun an yaktuba kamā 'allamullāh.

"Hai orang-orang yang beriman, apabila kamu bermu'amalah tidak secara tunai untuk waktu yang ditentukan, hendaklah kamu menuliskannya.."

Ayat Alquran yang memberikan gambaran tentang pemberian waktu jatuh tempo atas utang terdapat pada buku tafsir Al Mishbah (2002:732). Di dalam tafsiran surah Al-Baqarah ayat 282 di atas menyatakan setiap orang yang melakukan transaksi utang piutang tidak secara tunai diberi nasihat pokok yaitu yang terkandung dalam pernyataan "untuk waktu yang ditentukan" pernyataan tersebut mengisyaratkan bawah ketika seseorang berutang atau dalam penelitian ini perusahaan maka harus menetapakan masa pelunasanya. 
Islamy, et al/Jurnal Ekonomi Syariah Teori dan Terapan Vol. 5 No. 7 Juli 2018: 556-573; DETERMINAN DEBT MATURITY DEBT MATURITY PERUSAHAAN CONSUMER GOODS YANG TERDAFTAR DI ISSI

Keputusan pendanaan ditinjau dari jangka waktunya dapat dibagi menjadi dua: (1) jangka panjang, dan (2) jangka pendek (Sudana, 2011:3). Berdasarkan Tabel 1.1 dapat ditarik kesimpulan bahwa penggunaan proporsi penggunaan utang lebih didominasi oleh utang jangka pendek dari pada utang jangka panjang.

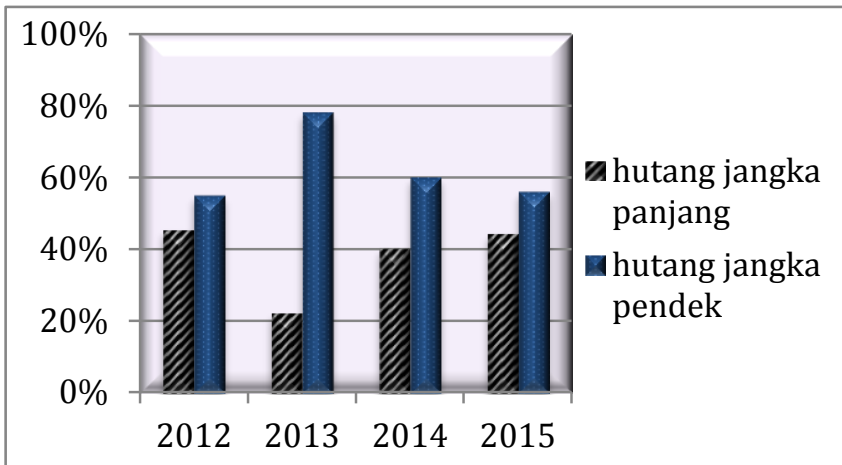

\section{Gambar 1.1}

Proporsi Perbandingan Utang Jangka Pendek dan Utang Jangka Panjang Sektor Manufaktur di Indonesia Tahun 2012- 2015 Perusahaan dalam menentukan proporsi penggunaan utang berdasarkan jangka waktunya tentunya didasarkan pada berbagai pertimbangan yang nantinya akan berdampak pada nilai perusahaan yang optimal. Perusahaan manufaktur bidang Consumer Goods yang listing di ISSI wajib menerapkan peraturan fatwa DSN seperti yang sudah dijelaskan di atas. Hal tersebut tersebut menjadi sesuatu yang menarik untuk dikaji, karena kebijakan penyesuaian fatwa DSN mengenai pilihan struktur maturitas utangnya ketika rasio utang berbasis bunga yang tidak diperbolehkan lebih dari $45 \%$ atas aset yang dimiliki hanya berlaku di Indonesia.
Dalam studi ini, penulis akan meneliti variabel-variabel yang diduga mempengaruhi perusahaan dalam menentukan pilihan struktur maturitas utang seperti firm size, profitability, tangibility dan asset maturity. Beberapa variabel tersebut didasarkan pada beberapa teori utama yang berkaitan dengan maturitas utang yaitu Agency Theory, Maturity Matching, Trade off, (Stephan et al., 2011) dalam Terra (2011) dan pecking order theory.

Rumusan masalah dalam penelitian ini adalah Apakah terdapat pengaruh secara simultan firm size, profitability, tangibility, asset maturity terhadap debt maturity structure perusahaan consumer goods yang terdaftar di ISSI periode 2012-2015 dan apakah terdapat pengaruh secara parsial firm size, profitability, tangibility, asset maturity terhadap debt maturity structure perusahaan consumer goods yang terdaftar di ISSI periode 2012-2015

Tujuan dari penelitian ini adalah untuk menguji dan menganalisis pengaruh firm size, profitability, tangibility, asset maturity terhadap debt maturity structure perusahaan consumer goods yang terdaftar di ISSI periode 2012-2015.

\section{Landasan Teori}

Teori Keagenan

Agency theory menjelaskan tentang pemisahan kepemilikan dan pengendalian usaha antara pemilik perusahaan dengan pengelola perusahaan. Penggunanan utang jangka pendek pada perusahaan berukuran kecil 
Islamy, et al/Jurnal Ekonomi Syariah Teori dan Terapan Vol. 5 No. 7 Juli 2018: 556-573; DETERMINAN DEBT MATURITY DEBT MATURITY PERUSAHAAN CONSUMER GOODS YANG TERDAFTAR DI ISSI

diduga dapat mengurangi biaya

Jatuh tempo utang dibagi menjadi keagenan.

\section{Maturity Maching}

Maturity matching merupakan suatu kebijakan keuangan yang mencocokan antara waktu jatuh tempo aset dan jatuh tempo kewajiban (Brigham, 266:2011).

\section{Trade-Off Theory}

Teori ini menjelaskan bahwa keputusan perusahaan menggunakan utang didasarkan pada keseimbangan antara pengehematan pajak dengan kemungkinan kebangkrutan atas penggunaan utang (Brigham dan Houston, 2007:459).

\section{Pecking Order Theory}

Teori ini menjelaskan bahwa perusahaan memiliki urutan-urutan dalam memenuhi kebutuhan pendanaan perusahaan. Pecking Order Theory menyatakan bahwa perusahaan lebih mengutamakan internal financing (laba ditahan).

\section{Pengertian Debt Maturity Structure}

Debt Maturity Structure merupakan sebuah kebijakan yang dilakukan oleh perusahaan dalam menentukan batas waktu jatuh tempo utang dalam melunasi sejumlah pinjaman kepada pihak kreditor yang dipengaruhi oleh besar kecilnya utang tersebut. Tekce (2011) menyatakan bawa maturitas utang perusahaan dipengaruhi oleh faktor spesifik perusahaan seperti rasio keuangan dan faktor spesifik Negara seperti inflansi, interest rate. utang jangka pendek dan utang jangka panjang. Menurut Sembeneli (1997) dalam Soekirman (2015) utang jangka pendek merupakan utang dengan jatuh tempo maksimal satu tahun. Sedangkan utang jangka panjang didefinisikan sebagian utang yang harus dibayar setelah satu tahun atau lebih.

\section{Faktor- Faktor yang Mempengaruhi Maturitas Utang \\ Firm Size}

Perusahaan besar memiliki biaya keagenan yang rendah, karena perusahaan skala besar memiliki akses lebih besar terhadap pasar modal dan memiliki keyakinan untuk mengatasi biaya transaksi serta memiliki power besar dalam bernegosiasi (Ozkan, 2000). Hal yang demikian dapat mempermudah perusahaan dengan ukuran lebih besar untuk memperoleh pinjaman atau dana pinjaman dari pihak luar. Titman dan Wessels (1998) memaparkan bahwa perusahaan besar mengambil keuntungan dari skala ekonomi dan cenderung lebih memilih utang jangka panjang karena perusahaan besar memiliki kemungkinan kebangkrutan atau kesulitan keuangan yang rendah dan memiliki akses pinjaman yang lebih mudah.

Profitability

Profitabilitas adalah kemampuan perusahaan dalam menghasilkan keuntungan pada tingkat penjualan, asset maupun modal saham selama periode tertentu. 
Islamy, et al/Jurnal Ekonomi Syariah Teori dan Terapan Vol. 5 No. 7 Juli 2018: 556-573; DETERMINAN DEBT MATURITY DEBT MATURITY PERUSAHAAN CONSUMER GOODS YANG TERDAFTAR DI ISSI

Tangibility

$$
\text { Tangibility }
$$

merupakan

perbandingan antara aktiva tetap terhadap total aktiva (Huang dan Song, 2015). Menurut Brigham dan Houston (2007:463) aktiva tetap yang dimiliki perusahaan dapat dijadikan jaminan untuk mendapatkan pinjaman apabila di masa yang akan datang perusahaan mengalami kesulitan finansial mengingat kondisi ekonomi yang fluktuatif.

\section{Asset maturity}

Asset maturity adalah umur ekonomis dari suatu aset dapat memberikan manfaat kepada perusahaan. Barnea et al. (1980) menyatakan bahwa memperpendek struktur maturitas utang agar cocok dengan struktur maturitas aset (maturity matching) dapat membantu untuk mengurangi biaya keagenan.

\section{Hubungan Antar Variabel}

\section{Pengaruh Firm size terhadap Struktur} Maturitas Utang

Ukuran perusahaan berpengaruh positif terhadap debt maturity structure (Hajiha, 2012). Titman dan Wessels (1998) mengatakan bahwa perusahaan besar mengambil keuntungan dari skala ekonomi dan cenderung lebih memilih utang jangka panjang dalam kebijakan utangnya.

$\mathrm{H}_{1}$ :Firm Size berpengaruh positif signifikan terhadap struktur maturitas utang perusahaan.

\section{Pengaruh Profitability terhadap Struktur Maturitas Utang}

Berdasarkan pecking order theory, profitabilitas berpengaruh negatif terhadap struktur maturitas utang. Leland dan Toft (1996) secara eksplisit mengatakan bahwa perusahaan dengan tingkat utang yang rendah cenderung memilih utang dengan maturitas yang pendek.

$\mathrm{H}_{2}$ : Profitability berpengaruh negatif signifikan terhadap struktur maturitas utang perusahaan.

\section{Pengaruh Tangibility terhadap Struktur Maturitas Utang}

Rajan dan Zingales (1995)

menyebutkan tangibility of assets possitevely related to debt maturity. Perusahaan dengan aset tetap yang rendah diyakini memiliki sedikit utang jangka panjang (Anika, 2011). Dari uraian tersebut dapat dirumuskan hipotesis, yaitu $\mathrm{H}_{3}$ :Tangibility berpengaruh positif signifikan terhadap struktur maturitas utang perusahaan.

\section{Pengaruh Asset Maturity terhadap Struktur Maturitas Utang Perusahaan}

Asset maturity berpengaruh positif terhadap struktur maturitas utang (Hajiha, 2012). Hal ini menunjukkan bahwa dalam pengambilan keputusan pendanaan perusahaan harus melakukan prinsip maturity matching. Perusahaan dengan umur ekonomis aset yang panjang cenderung memiliki utang dengan jatuh tempo yang panjang pula.

$\mathrm{H}_{4}$ : Asset Maturity berpengaruh positif signifikan terhadap struktur maturitas utang perusahaan.

\section{Model Analisis}

$Y(D E B M A)=\alpha+\beta 1(\text { SIZ })_{\text {it }}+\beta 2(\text { PRO })_{\text {it }}+\beta 3(\text { TAN })_{\text {it }}+$

$$
\beta 4(\mathrm{AMAT})_{\text {it }}+\mu
$$

\section{Metode Penelitian}


Islamy, et al/Jurnal Ekonomi Syariah Teori dan Terapan Vol. 5 No. 7 Juli 2018: 556-573; DETERMINAN DEBT MATURITY DEBT MATURITY PERUSAHAAN CONSUMER GOODS YANG

TERDAFTAR DI ISSI

Pendekatan Penelitian

Pendekatan yang digunakan

pada penelitian ini adalah pendekatan kuantitatif.

\section{Identifikasi Variabel}

Berdasarkan rumusan masalah penelitian, maka variabel endogen dalam penelitian ini adalah debt maturity structure dan variabel eksogenya adalah firm size, profitability, tangibility dan asset maturity.

\section{Definisi Operasional}

Struktur maturitas utang perusahaan (Debt Maturity Structure) adalah jatuh tempo utang yang digunakan oleh perusahaan dan dipengaruhi oleh besar kecilnya utang tersebut. panjang dan utang jangka pendek.

Dapat diukur dengan rumus berikut:

Debt Maturity Structure $=\frac{\text { Long Term Debt }}{\text { Total Debt }}$

Pada penelitian ini ukuran perusahaan diukur dengan menggunakan logaritma natural dari total aktiva pada akhir tahun.

Firm Size $=\ln$ (Total Asset)

Profitabilitas adalah kemampuan sebuah perusahaan dalam menghasilkan laba setelah pajak dengan memanfaatkan asset yang dimiliki perusahaan tersebut.

Profitability $=\frac{\text { earning after tax }}{\text { Total Asset }}$

Tangibility adalah jumlah aset tetap yang dapat digunakan oleh perusahaan sebagai jaminan atas pinjaman yang diterbitkan.
Tangibility $=\frac{\text { Fixed Assets }}{\text { Total Asset }}$

Asset Maturity

Maturitas Aset adalah umur ekonomis dari suatu asset tetap dapat memberikan manfaat bagi perusahaan.

$$
\text { Asset Maturity }=\frac{\text { Fixed Assets }}{\text { Depreciation }}
$$

\section{Jenis dan Sumber Data}

Data yang digunakan dalam penelitian ini adalah data sekunder berupa laporan keuangan perusahaan yang telah go public yang terdaftar di ISSI dan merupakan data panel yang menggabungkan time series dan data cross section. Data sekunder adalah data yang diperoleh dari sumber kedua dan biasanya sudah siap pakai (Widiarjono, 2005:8). Sumber data utama yang digunakan dalam penelitian ini diperoleh dari BEl yang dapat diakses melalui www.idx.co.id.

\section{Populasi dan Sampel}

Populasi adalah wilayah generalisasi yang terdiri atas subyek yang mempunyai kuantitas dan karateristik tertentu yang diterapkan peneliti untuk dipelajari dan ditarik kesimpulannya (Anshori dan Iswati, 2009:92).

Populasi yang digunakan dalam penelitian ini adalah perusahaan yang terdaftar di Indeks Saham Syariah Indonesia.

\section{Sampel}

Teknik sampling yang digunakan dalam penelitian ini adalah purposive sampling. Teknik pengambilan dengan cara ini bertujuan untuk mencapai batasan yang diharapakan dari penelitian ini. Batasan kriteria penentuan sampel dalam penelitian ini adalah: 
Islamy, et al/Jurnal Ekonomi Syariah Teori dan Terapan Vol. 5 No. 7 Juli 2018: 556-573; DETERMINAN DEBT MATURITY DEBT MATURITY PERUSAHAAN CONSUMER GOODS YANG TERDAFTAR DI ISSI

a. Perusahaan yang bergerak pada industri barang konsumsi /consumer goods) dan harus menerbitkan dan mempublikasikan laporan keuangan setiap akhir tahun periode yang memuat informasi-informasi tentang variable yang dibutuhkan dalam penelitian ini.

\section{Tabel 2}

\section{Daftar Perusahaan Consumer Goods yang}

Memenuhi Kriteriia Sampel periode 2012-

2015

\begin{tabular}{|l|l|}
\hline NO & \multicolumn{1}{|c|}{ Nama Perusahaan } \\
\hline 1 & PT Akasha Wira International Tbk. \\
\hline 2 & PT Tiga Pilar Sejahtera Food Tbk. \\
\hline 3 & PT Darya-Varia Labotaria Tbk. \\
\hline 4 & $\begin{array}{l}\text { PT Indofood CBP Sukses Makmur } \\
\text { Tbk. }\end{array}$ \\
\hline 5 & PT Indofood Sukses Makmur Tbk. \\
\hline 6 & PT Kimia Farma (Persero) Tbk. \\
\hline 7 & PT Kedawung Setia Industrial Tbk. \\
\hline 8 & PT Kalbe Farma Tbk. \\
\hline 9 & PT Merck Tbk. \\
\hline 10 & PT Mayora Indah Tbk. \\
\hline 11 & PT Priydam Farma Tbk. \\
\hline 12 & PT Nippon Indosari Corpindo Tbk. \\
\hline 13 & PT Sekar Laut Tbk. \\
\hline 14 & $\begin{array}{l}\text { PT Taisho } \\
\text { Indonesia Tbk. Pharmaceutical }\end{array}$ \\
\hline 15 & PT Siantar Top Tbk. \\
\hline 16 & PT Mandom Indonesia Tbk. \\
\hline 17 & PT TempoScan Pacific Tbk. \\
\hline 18 & $\begin{array}{l}\text { PT Ultrajaya Milk Industry \& } \\
\text { Trading Company Tbk. }\end{array}$ \\
\hline 19 & PT Unilever Indonesia Tbk. \\
\hline
\end{tabular}

\section{Teknis Analisis}

Model yang dipakai untuk mengolah data dalam penelitian ini adalah dengan menggunakan Panel Data Regression Model. Secara sederhana menurut Ghozali dan Ratmono (2013:231) data panel dapat didefinisikan sebagai kumpulan data di mana perilaku unit cross-sectional.

Menurut Gujarati (2003:559-603), terdapat tiga metode estimasi yang bisa digunakan dalam metode regresi data panel, yaitu pendekatan PLS lalu kedua dengan menggunakan pendekatan Fixed Effect (efek tetap), dan pendekatan terakhir yaitu Random Fffect (efek acak).

Pemilihan model estimasi dalam regresi data panel melalui dua langkah pengujian. Pertama, untuk menenentukan antara model PLS dengan FEM menggunakan Uji Chow. Kedua, uji Hausman digunakan untuk menentukan antara FEM antara REM. Menurut Gujarati (2003:643) Rumus uji F dilakukan dengan rumus sebagai berikut :

$$
F=\frac{R_{u r}^{2}-R_{r}^{2} /(m)}{\left(1-R_{u r}^{2}\right) /(n-k)}
$$

Hipotesis nol dari pada $F$ test tersebut adalah :

$\mathrm{H}_{0}=P L S$

$\mathrm{H}_{1}=F E M$

Dari persamaan 3.10 jika kita mendapatkan hasil nilai Fhitung $>$ Ftable pada tingkat keyakinan $(\alpha)$ tertentu, maka $\mathrm{H}_{0}$ yang menyatakan menggunakan model Pooled Least Square ditolak. Sehingga $\mathrm{H}_{1}$ yang menyatakan menggunakan model Fixed Effect diterima.

Selanjutnya, uji Hausman untuk menentukan antara metode fix effect dengan metode random effect. Hipotesis yang digunakan dalam uji Hausman adalah:

$H_{0}=$ REM

$\mathrm{H}_{1}=\mathrm{FEM}$

Apabila pada uji Hausman didapatkan hasil chi square $_{\text {hitung }}>$ chi square table dan $\mathrm{p}$-value signifikan, maka $\mathrm{H}_{0}$ ditolak dan fixed effect model (FEM) lebih tepat untuk digunakan sebagai model penelitian. 
Islamy, et al/Jurnal Ekonomi Syariah Teori dan Terapan Vol. 5 No. 7 Juli 2018: 556-573; DETERMINAN DEBT MATURITY DEBT MATURITY PERUSAHAAN CONSUMER GOODS YANG TERDAFTAR DI ISSI

\section{Hasil dan Pembahasan}

Deskripsi Variabel Penelitian

Tabel 4.1

Output Eviews 6.0 Statistik Desktriptif

\begin{tabular}{|c|c|c|c|c|}
\hline $\begin{array}{l}\text { Varia } \\
\text { bel }\end{array}$ & $\begin{array}{l}\text { Rata- } \\
\text { rata }\end{array}$ & $\begin{array}{c}\text { Stand } \\
\text { ar } \\
\text { Devia } \\
\text { si }\end{array}$ & $\begin{array}{l}\text { Nilai } \\
\text { Maksi } \\
\text { mum }\end{array}$ & Nilai Minimu \\
\hline $\begin{array}{l}\text { DEB } \\
\text { MA }\end{array}$ & 0.2991 & $\begin{array}{c}0.174 \\
3\end{array}$ & 0.739 & 0.0599 \\
\hline SIZE & 28.525 & $\begin{array}{c}1.587 \\
9\end{array}$ & 32.15 & 25.634 \\
\hline PROF & 0.1274 & $\begin{array}{c}0.100 \\
6\end{array}$ & 0.4150 & 0.0097 \\
\hline TAN & 0.4335 & $\begin{array}{c}0.148 \\
6\end{array}$ & 0.8175 & 0.1559 \\
\hline MAT & 15.892 & $\begin{array}{c}7.355 \\
1 \\
\end{array}$ & 36.070 & 6.4428 \\
\hline \multicolumn{5}{|c|}{ Sumber: Ouput Eviews (diolah) } \\
\hline \multicolumn{5}{|c|}{ Tabel 4.2} \\
\hline
\end{tabular}

\begin{tabular}{|c|c|c|c|c|}
\hline & & 0 & & 5 \\
\hline & Prob. & 0.0001 & 0.0678 & 0.7490 \\
\hline \multirow[t]{4}{*}{$\begin{array}{l}\text { TAN } \\
\left(X_{3}\right)\end{array}$} & Koefesien & $\begin{array}{c}0.53359 \\
2\end{array}$ & 0.437155 & $\begin{array}{c}0.12194 \\
2\end{array}$ \\
\hline & Std. Error & $\begin{array}{c}0.11632 \\
3\end{array}$ & 0.264391 & $\begin{array}{c}0.17031 \\
2\end{array}$ \\
\hline & t-Statistik & $\begin{array}{c}4.58717 \\
6\end{array}$ & -1.653444 & $\begin{array}{c}0.71599 \\
3\end{array}$ \\
\hline & Prob. & 0.0000 & 0.1042 & 0.4763 \\
\hline \multirow[t]{4}{*}{$\begin{array}{l}\text { MAT } \\
\left(\mathrm{X}_{4}\right)\end{array}$} & Koefesien & $\begin{array}{c}- \\
0.00036 \\
3\end{array}$ & 0.007465 & $\begin{array}{c}0.00412 \\
6\end{array}$ \\
\hline & Std. Error & $\begin{array}{c}0.00286 \\
4\end{array}$ & 0.003370 & $\begin{array}{c}0.00287 \\
9\end{array}$ \\
\hline & t-Statistik & $\begin{array}{c}- \\
0.12684 \\
2\end{array}$ & 2.214973 & $\begin{array}{c}1.43303 \\
3\end{array}$ \\
\hline & Prob & 0.8994 & 0.0311 & 0.1562 \\
\hline \multicolumn{2}{|l|}{$\left(R^{2}\right)$} & $\begin{array}{c}0.45288 \\
8\end{array}$ & 0.920651 & $\begin{array}{c}0.08156 \\
1\end{array}$ \\
\hline \multicolumn{2}{|c|}{ Prob (F-Stat) } & 0.00000 & 0.00000 & 0.19003 \\
\hline
\end{tabular}

Sumber: Data diolah peneliti, lampiran 3,4

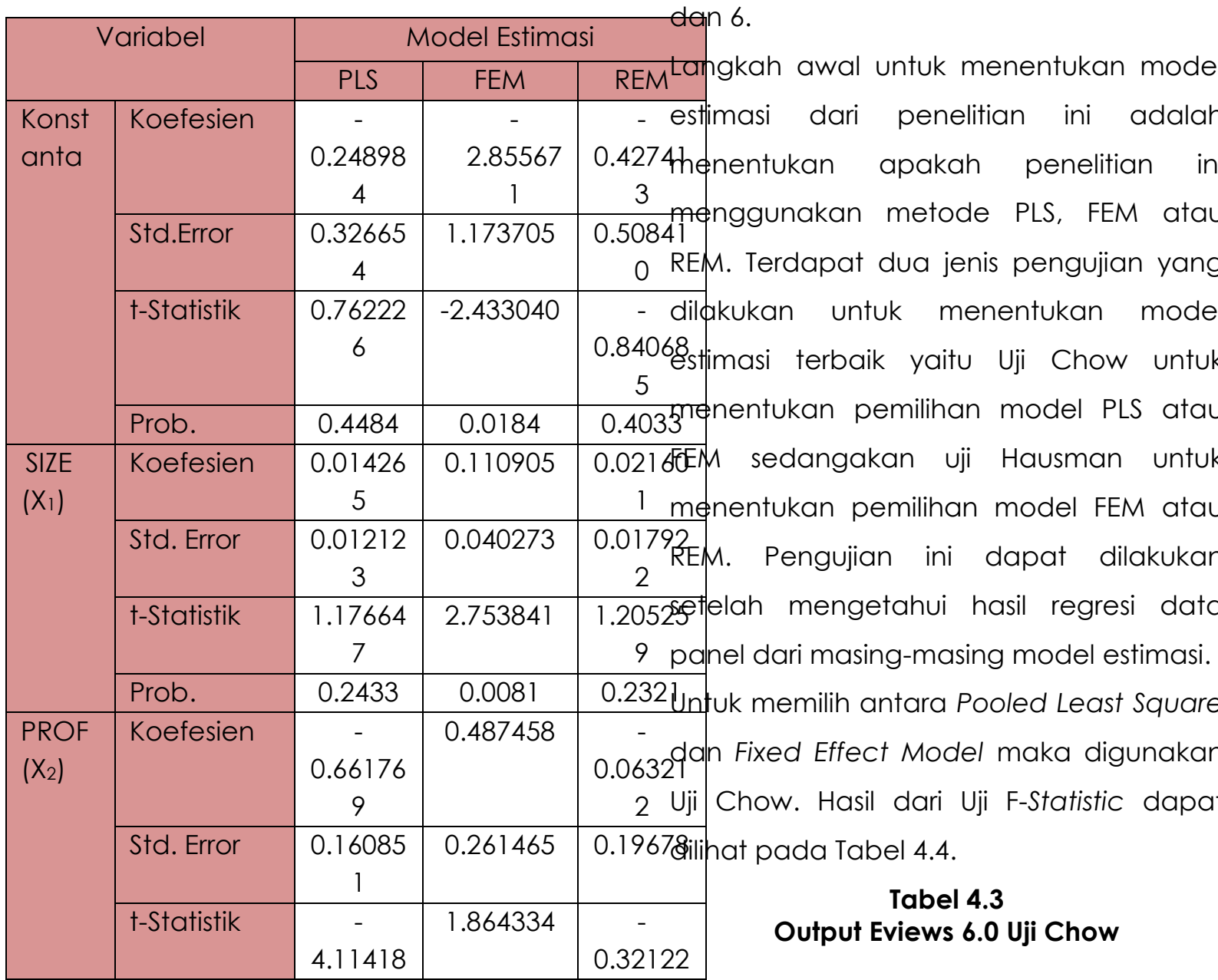


Islamy, et al/Jurnal Ekonomi Syariah Teori dan Terapan Vol. 5 No. 7 Juli 2018: 556-573; DETERMINAN DEBT MATURITY DEBT MATURITY PERUSAHAAN CONSUMER GOODS YANG

TERDAFTAR DI ISSI

\begin{tabular}{cccc}
\hline $\begin{array}{c}\text { Effects } \\
\text { Test }\end{array}$ & Statistic & d.f. & Prob \\
\hline $\begin{array}{c}\text { Cross- } \\
\text { section }\end{array}$ & 17.357646 & $(18,53)$ & 0,0000 \\
\hline
\end{tabular}

Sumber: Data diolah peneliti, lampiran 4.

Hipotesis :

$\mathrm{H}_{0} \quad=$ Model Pooled Least Square (PLS)

$\mathrm{H}_{1} \quad=$ Model Fixed Effect (FEM)

Berdasarakan hasil pengujian yang tertera pada Tabel 4.5 maka hasil uj FStatistik yang diperoleh nilai probabilitas sebesar 0,0000 . Nilai probabilitasnya lebih kecil jika dibandingkan dengan tingkat signifikansi (5\%). Berdasarkan uji tersebut dapat disimpulkan bahwa FEM lebih tepat untuk digunakan dalam penelitian.

Tahapan selanjutnya adalah menguji model yang lebih tepat antara FEM dan REM untuk digunakan dalam penelitian ini. Pengujian dilakukan dengan menggunakan Uji Hausman, Hipotesis dalam Uji Hausman adalah sebagai berikut:

$\mathrm{H}_{0} \quad=$ Random Effect Model (REM)

$\mathrm{H}_{1} \quad=$ Fixed Effect Model (FEM)

Apabila probabilitas hasil $\mathrm{uji}$ Hausman kurang dari tingkat signifikansi (5\%) maka $H_{0}$ ditolak dan $H_{1}$ diterima, sehingga FEM lebih tepat dibandingkan REM demikian pula sebaliknya. Berikut adalah hasil Uji Hausman dengan EViews6.

Tabel 4.4

Output Eviews 6.0 Hasil Uji Hausman

\begin{tabular}{cccc}
\hline $\begin{array}{c}\text { Test } \\
\text { Summary }\end{array}$ & $\begin{array}{c}\text { Chi-Sq. } \\
\text { Statistic }\end{array}$ & $\begin{array}{c}\text { Chi- } \\
\text { Sq.d.f }\end{array}$ & Prob. \\
\hline $\begin{array}{c}\text { Cross- } \\
\text { section }\end{array}$ & 27,251864 & 4 & 0.0000 \\
\hline
\end{tabular}

Sumber: Data diolah peneliti, lampiran 6.

Berdasarkan uji Hausman yang

terlihat pada Tabel 4.6, maka diperoleh probabilitas sebesar 0.0000 . Jika nilai probabilitas lebih kecil dari pada tingkat signifikasni (5\%) maka $\mathrm{H}_{0}$ yang menyatakan random effect model ditolak. Berdasarkan uji tersebut dapat disimpulkan bahwa FEM lebih tepat untuk digunakan dalam penelitian ini dibandingkan dengan REM.

Tabel 4.5

Output Eviews 6.0 Regresi Model FEM

\begin{tabular}{|c|c|c|c|c|}
\hline Variabel & $\begin{array}{c}\text { Koefesie } \\
n\end{array}$ & $\begin{array}{l}\text { Std. } \\
\text { Error }\end{array}$ & $\begin{array}{c}\mathbf{t}- \\
\text { Statisti } \\
\mathbf{k}\end{array}$ & Prob \\
\hline $\begin{array}{c}\text { Konstant } \\
a\end{array}$ & -2.8556 & $\begin{array}{c}1.173 \\
7 \\
\end{array}$ & -2.433 & $\begin{array}{c}0.01 \\
8 \\
\end{array}$ \\
\hline SIZE & 0.1109 & $\begin{array}{c}0.040 \\
2\end{array}$ & 2.7538 & $\begin{array}{c}0.00 \\
8\end{array}$ \\
\hline PROF & 0.4874 & $\begin{array}{c}0.261 \\
4\end{array}$ & 1.8643 & $\begin{array}{c}0.06 \\
7\end{array}$ \\
\hline TAN & -0.4371 & $\begin{array}{c}0.264 \\
3 \\
\end{array}$ & 1.6534 & $\begin{array}{c}0.10 \\
4 \\
\end{array}$ \\
\hline MAT & 0.007465 & 0.003 & 2.214 & 0.03 \\
\hline \multicolumn{5}{|c|}{ Fixed Effect } \\
\hline$\left(R^{2}\right)$ & \multicolumn{4}{|c|}{0.920651} \\
\hline $\begin{array}{l}\text { Prob. (F- } \\
\text { Stat) }\end{array}$ & \multicolumn{4}{|c|}{0.00000} \\
\hline
\end{tabular}

Sumber: Ouput Eviews (diolah)

Uji F- Statistik

Uji F-Statistik digunakan untuk melihat pengaruh variabel eksogen terhadap variabel endogen secara simultan atau bersama-sama. Hipotesis dari uji F-Statistik adalah sebagai berikut:

$H_{0}: \beta=\beta 1=\beta 2=\beta 3=\beta 4 \ldots \beta k=0$ artinya semua variabel eksogen secara bersamasama tidak berpengaruh terhadap variabel endogen.

$\mathrm{H}_{1}: \beta \neq \beta 1 \neq \beta 2 \neq \beta 3 \neq \beta 4 \neq \cdots \neq \beta k \neq 0$

artinya semua variabel eksogen secara bersama-sama berpengaruh terhadap variabel endogen.

Berdasarkan Tabel hasil regresi data panel pada pada model estimasi 
Islamy, et al/Jurnal Ekonomi Syariah Teori dan Terapan Vol. 5 No. 7 Juli 2018: 556-573; DETERMINAN DEBT MATURITY DEBT MATURITY PERUSAHAAN CONSUMER GOODS YANG TERDAFTAR DI ISSI

yang dipiliih yakni FEM didapatkan probabilitas F-statistik 0,0000 yang lebih kecil dari tingkat signifikansi (5\%), dengan demikian variabel eksogen (firm size, profitability, tangibility, asset maturity) berpengaruh secara bersama-sama terhadap variabel endogen debt maturity structure.

Uji t-Statistik

Uji t-Statistik digunakan untuk melihat pengaruh variabel eksogen terhadap variabel endogen secara parsial. Hipotesis dari uji t-statistik adalah sebagai berikut :

Ho: Variabel eksogen tidak berpengaruh secara parsial terhadap variabel endogen.

$H_{1}$ : Variabel eksogen berpengaruh secara parsial terhadap variabel endogen.

Berdasarkan Tabel regresi data panel pada model estimasi yang dipiliih yakni FEM didapatkan hasil bahwa dua dari empat variabel eksogen yaitu Firm size dan Asset maturity berpengaruh signifikan secara parsial terhadap DEBTMA di tingkat signifikansi lima persen (5\%) atau 0.05. Namun, apabila menggunakan tingkat signifikansi (10\%) atau 0,1 maka tiga dari empat variabel yaitu firm size, profitability dan tangibility berpengaruh signifikan terhadap debt maturity structure.

\subsubsection{Koefesien Determinasi $\left(\mathbf{R}^{2}\right)$}

Koefesien determinasi

digunakan untuk mengetahui kemampuan variabel eksogen dalam menjelaskan variabel endogen dalam model estimasi. Berdasarkan hasil pengolahan data untuk FEM diperoleh nilai koefesien detreminasi $\left(R^{2}\right)$ sebesar 0.920651 (92,06\%). Nilai ini menunjukkan bahwa variabel Debt Maturity Structure sebagai variabel endogen dalam model penelitian ini dapat dijelaskan sebesar 92,06\% oleh variabel eksogen dalam model penelitian. Sedangkan sisanya dipengaruhi oleh variabel-variabel lain diluar model pada penelitian sebesar $7,93 \%$.

\section{Pengaruh Firm Size terhadap Debt Maturity Structure}

Berdasarkan hasil penelitian ini diketahui firm size berpengaruh positif signifikan terhadap debt maturity structure perusahaan. Hal ini menunjukkan bahwa besar kecilnya ukuran perusahaan akan mempengaruhi struktur maturitas utang. Hasil dalam penelitian ini sesuai dengan hipotesis yang rumuskan serta mendukung hasil penelitian yang dilakukan oleh Stohs dan Maurer (1996), Hajiha (2012), Soekirman (2015).

Hajiha (2012) Perusahaan besar cenderung lebih mudah untuk mendapatkan pinjaman dari pihak ketiga, karena kemampuannya untuk mengakses pihak lain dan memiliki akses yang lebih mudah dalam pasar modal hal yang demikian akan memberikan kemudahan pada perusahaan besar untuk meningkatkan utang jangka panjang. Selain itu, Abdul Halim (2007) menyatakan bahwa semakin besar ukuran perusahaan, maka kecenderungan untuk menggunakan modal asing juga semakin besar. Hal ini disebabkan karena 
Islamy, et al/Jurnal Ekonomi Syariah Teori dan Terapan Vol. 5 No. 7 Juli 2018: 556-573; DETERMINAN DEBT MATURITY DEBT MATURITY PERUSAHAAN CONSUMER GOODS YANG TERDAFTAR DI ISSI

perusahaan besar membutuhkan dana yang besar pula untuk menunjang kebutuhan operasional dan ekspansi bisnisnya dan salah satu alternatif pemenuhannya dengan menggunakan utang. Perusahaan besar cenderung menggunakan lebih banyak utang jangka panjang untuk memenuhi kebutuhan keuangan perusahaan. (Jalilvand dan Harris, 1984)

Mai (2006) menyatakan alasan yang mendukung hasil penelitian ini adalah bahwa perusahaan skala kecil lebih sulit untuk memperoleh pinjaman dari pihak luar jika dibandingkan perusahaan besar, hal demikian dikarenakan perusahaan kecil kurang memiliki pandangan di mata kreditor. Hal ini terkait dengan tingkat kepercayaan yang diberikan oleh pihak kreditor dalam memberikan pinjaman kepada perusahaan besar dibandingkan dengan kepercayaan pada perusahaan kecil. Pernyataan tersebut didukung oleh Sukianto (2013), bahwa perusahaan dengan ukuran besar memiliki risk default yang rendah sehingga pihak kreditor akan memberikan jatuh tempo pembayaran utang yang panjang. Sebaliknya, upaya kreditor dalam mengendalikan risiko gagal bayar oleh perusahaan kecil yaitu dengan membatasi panjangnya maturitas utang yang diambil.

$$
\text { Basuki (2006) menyatakan }
$$

perusahaan dengan total aktiva yang besar menunjukkan bahwa perusahaan tersebut telah mencapai tahap kedewasaan di mana dalam fase ini arus kas yang dimiliki perusahaan stabil dan dianggap memiliki prospek bisnis yang yang baik dalam jangka waktu yang lama sehingga perusahaan tersebut dipandang mampu menghadapi krisis dalam menjalankan usahanya. Sejalan dengan pernyataan tersebut, Titman \& Wessels (1998) memaparkan bahwa perusahaan besar mengambil keuntungan dari skala ekonomi dan cenderung lebih memilih utang jangka panjang karena perusahaan besar mampu mengatasi biaya transaksi dan memiliki akses pinjaman lebih mudah dibandingkan dengan perusaahaan kecil.

\section{Pengaruh Profitability terhadap Debt Maturity Structure}

Berdasarkan hasil analisis koefesien

parsial menunjukkan hubungan yang positif dan signifikan pada variabel profitability terhadap debt maturity structure pada tingkat signifikansi $10 \%$. Adanya hubungan positif antara tingkat profitabilitas dengan struktur maturitas utang artinya bahwa setiap kenaikan tingkat profitabilitas akan meningkatkan maturitas utang perusahaan. Hasil ini sesuai dengan trade off theory yang memprediksi akan adanya hubungan positif antara profitability terhadap utang jangka panjang.

Hubungan positif dan signifikan antara profitabilitas dengan debt maturity structure dalam penelitian ini sejalan dengan penelitian yang dilakukan oleh Hajiha (2012). Modigliani dan Miller (1963) menyatakan bahwa bunga utang dapat digunakan sebagai alat untuk 
Islamy, et al/Jurnal Ekonomi Syariah Teori dan Terapan Vol. 5 No. 7 Juli 2018: 556-573; DETERMINAN DEBT MATURITY DEBT MATURITY PERUSAHAAN CONSUMER GOODS YANG TERDAFTAR DI ISSI

mengurangi pajak penghasilan yang harus dibayar perusahaan. Adanya interest tax shield menyebabkan perusahaan cenderung menggunakan utang dalam jumlah yang tinggi. Sejalan dengan pernyataan tersebut, Hong dan Jason (2006) menyatakan perusahaan yang memiliki profitabilitas tinggi akan melakukan aktivitas pendanaan dengan menggunakan utang jangka panjang untuk memperoleh manfaat dari pemghematan pajak. Bunga dapat mengurangi keuntungan kena pajak sehingga pajak yang dibayarkan lebih kecil (Sudana, 2011: 208).

Brigham dan Houston (2011:33) mengatakan dalam konsep trade off theory dijelaskan juga antara manfaat dari penggunaan utang dengan biaya kebangkrutan dan biaya keagenan. Teori ini muncul setelah Modigliani Miller (MM) menyadari bahwa terdapat keuntungan dari penggunaan utang. Implikasi trade off theory mengatakan bahwa perusahaan dengan profitabilitas yang tinggi cenderung menggunakan utang yang tinggi pula guna mendapatkan keuntungan dari pembayaran bunga yang nantinya akan berdampak pada rendahnya pembayaran pajak (Hajiha, 2012). Teori ini mengasumsikan bahwa lingkungan eksternal perusahaan mengalami kondisi yang stabil (tidak berubah), sehingga untuk mencapai utang yang optimal perusahaan hanya mempertimbangkan antara keuntungan memakai utang dan biaya kesulitan kevangan. Sejauh manfaat yang didapatkan dari berutang besar, maka penggunaan utang dianjurkan. Dalam preskpektif Islam, utang atau gardh diperbolehkan namun dengan batasanbatasan tertentu. Batasan penggunaan utang pada perusahaan berbasis Islam telah diatur dalam Peraturan BAPEPAM dan LK yang direfleksikan melalui Surat Keputusan Ketua No. KEP-208/BL/2012 tentang kriteria Penerbitan Daftar Efek Syariah. Dalam peraturan disebutkan yang mana salah satu poinnya adalah total utang berbasis bunga dibandingkan dengan total asset tidak lebih dari $45 \%$. Artinya jika perusahaan ingin mendaftarkan saham syariahnya, perusahaan harus mampu mengelola rasio debt to assetnya. Di mana aset perusahaan maksimal hanya bisa didanai oleh utang sebesar 45\%. Dari aturan tersebut dapat ditarik kesimpulan bahwa penggunaan utang adalah boleh namun tetap harus dibatasi penggunaannya. Perusahaan dengan profitabilitas yang tinggi yang terdaftar dalam ISSI tentunya harus menerapakan peraturan tersebut agar tetap sesuai dengan kaidah-kaidah syariah Islam. Utamanya dalam Islam, seorang umat diharuskan selalu bersikap hati-hati dalam bertindak, agar apa yang dilakukannya menjadi berkah. Sebagaimana Hadits riwayat berikut ini :

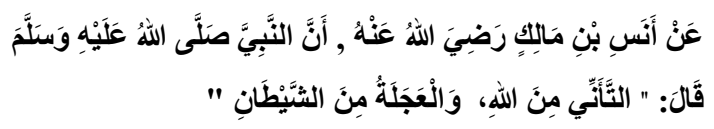

"at-ta'annī mina 'Ilāhi wa 'I-'ajalatu mina 's-syaițāni"

Artinya: 
Islamy, et al/Jurnal Ekonomi Syariah Teori dan Terapan Vol. 5 No. 7 Juli 2018: 556-573; DETERMINAN DEBT MATURITY DEBT MATURITY PERUSAHAAN CONSUMER GOODS YANG TERDAFTAR DI ISSI

"(Sikap) pelan-pelan itu dari Allah dan

(sikap) tergesa-gesa itu dari syaithan."

Hadits tersebut secara tersirat

menjelaskan bahwa Islam telah

menyerukan kepada umatnya agar selalu senantiasa bersikap hati-hati dan waspada dalam menjalankan segala aktivitas. Kaitannya dengan proses pengambilan keputusan pendanaan bagi perusahaan adalah seorang manajer harus berhati-hati dalam menentukan sumber pendanaan yang tepat bagi perusahaan. Apabila perusahaan menggunakan sumber pendanaan eksternal berupa utang maka perusahaan juga harus menetapkan maturitas utangnya. Keduanya memiliki keterkaitan satu sama lain. Manajer harus melakukan pengamatan tentang kondisi keuangan perusahaan, pertimbangan yang tepat hingga perencanaan yang matang sebelum mengambil keputusan pendanaan, karena hal tersebut akan menentukan kondisi perusahaan kedepannya.

\section{Pengaruh Tangibility terhadap Debt Maturity Structure}

Pada penelitian ini tangibility berpengaruh negatif dan tidak signifikan terhadap debt maturity structure (struktur maturitas utang). Pengaruh antara variabel tangibility yang tidak signifikan dikarenakan dalam memperoleh utang perusahaan tidak hanya memperhatikan aset tetap yang nantinya akan dijadikan sebagai jaminan. Perusahaan memahami bahwa kreditor tidak hanya mempertimbangkan aset tetap yang dimiliki perusahaan dalam memberikan pinjaman. Namun, ada prinsip-prinsip lain yang digunakan oleh kreditor dalam memberikan pinjaman kepada calon debitur. Adapun prinsip-prisip yang juga menjadi bahan pertimbangan oleh pihak kreditor dalam memberikan pinjaman selain collaterral berupa aset tetap yaitu character, capacity, capital dan condition of economic atau dalam istilah ekonomi dikenal sebagai 5C (Zaini, 2014:203). Oleh sebab itu perusahaan dalam praktinya juga tidak hanya memperhatikan aset tetap guna mendapatkan utang jangka panjang, namun perusahaan harus mampu menjaga reputasi perusahaanya untuk memenuhi ke empat prinsip yg lain. Perusahaan dapat menjaga reputasi perusahaanya agar memperoleh pinjaman dengan memperhatikan prinsip karakter. Character yang dimaksud dalam prinsip di atas berkaitan dengan penilaian karakter calon debitur. Hal tersebut dilakukan oleh kreditor untuk menyimpulkan apakah calon debitur ini memiliki sifat yang jujur, beriktikad baik, dan dapat memenuhi utangnya pada saat jatuh tempo. Dalam prespektif Islam, hukum utang piutang diperbolehkan (mubah), namun wajib hukumnya untuk membayar utang yang diterima. Jika perusahaan memilih pendanaan eksternal berupa utang maka wajib hukumnya untuk melunasi utang tersebut. Hal ini diperjelas dengan Hadits berikut ini : 
Islamy, et al/Jurnal Ekonomi Syariah Teori dan Terapan Vol. 5 No. 7 Juli 2018: 556-573; DETERMINAN DEBT MATURITY DEBT MATURITY PERUSAHAAN CONSUMER GOODS YANG TERDAFTAR DI ISSI

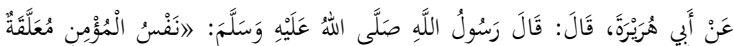

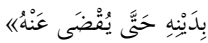

"nafsul-mu'minimu'allaqatun

bi-dainihi hattā yuqd̄a "anhu"

Artinya:

Jiwa orang mukmin bergantung pada utangnya hingga dilunasi utangnya. HR Sunan Ibnu Majah.

Hadits di atas menerangkan betapa wajibnya bagi setiap umat untuk melunasi utangnya. Telah dijelaskan pada salah satu Hadits bahwa seorang muslim jiwanya tergantung pada utang hingga dilunasi. Sehingga wajib hukumnya bagi setiap muslim apabila mempunyai utang untuk melunasinya. Utang merupakan sebuah kewajiban. Dengan membayar utang maka dapat dikatakan bahwa debitur mempermudah urusan orang yang memberi utang sehingga debitur mendapat kepercayaan lebih dari pihak kreditor. Capacity dalam hal ini merupakan suatu penilaian kepada calon debitur mengenai kemampuan melunasi kewajiban-kewajibannya dari kegiatan usaha yang dilakukannya. Adapun capital adalah kondisi kekayaan yang dimiliki oleh perusahaan yang dikelolanya. Penilaian ini dilakukan dengan melihat posisi keuangan calon debitur secara keseluruhan termasuk aliran kas, baik untuk masa lalu maupun proyeksi pada masa yang akan datang. Dari laporan keuangan perusahaan bisa dinilai apakah layak calon debitur diberi pembiayaan atau tidak.. Dan terakhir, condition of economic. Jaminan berupa aset tetap perusahaan bukan satu-satunya unsur yang dipertimbangkan oleh pihak debitur namun hanya sebagai penguat saja. Islam mengajarkan umatnya untuk menghindari utang namun apabila dalam keadaan terpaksa diperbolehkan, namun wajib hukumnya untuk segera melunasi. Seseorang yang memberi pinjaman (kreditor) dapat meminta jaminan atas utang yang diberikan jika dipandang perlu. (Muhammad, 2014:333) Hal ini tertuang dalam Alquran surah Al-Baqarah ayat 283 dan diperkuat dengan Hadits Bukhari Muslim berikut ini :

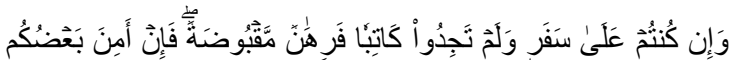

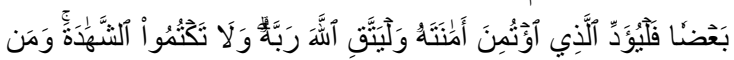

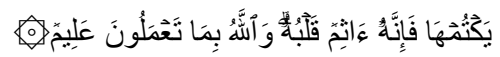

Wa in kuntum 'alā safarin walam tajid $\bar{u}$ kātiban farihānum-maqbūḍah. Fain amina ba'ḍkum ba'ḍan falyu-addi'l-lazi' tumina amānatahu walyattaqi'l-Läha rabbah. Wa Ia taktumu'sy-syahādah. Wa man yaktumhā fainnahu āsimun qalbuh. Wa'lLāhu bimā †a'malūna 'alīm.

"Jika Kamu dalam perjalanan (dan bermumalah tidak secara tunai) sedang kamu tidak memperoleh seorang penulis, maka hendaklah ada barang tangguhan yang dipegang (oleh orang yang berpiutang). Akan tetapi jika sebagian kamu mempercayai sebagian yang lain, maka hendaklah yang dipercayai itu untuk menunaikan amanatnya (hutannya) (Departemen Agama Rl, 2012)

Berdasarkan tafsir Al-Mishbah dikatakan bahwa pemberian barang sebagai jaminan tidak harus dilakukan, hal tersebut didukung oleh kalimat "sebagian 
Islamy, et al/Jurnal Ekonomi Syariah Teori dan Terapan Vol. 5 No. 7 Juli 2018: 556-573; DETERMINAN DEBT MATURITY DEBT MATURITY PERUSAHAAN CONSUMER GOODS YANG TERDAFTAR DI ISSI

kamu mempercayai sebagian yang lain, maka hendaklah yang dipercayai itu untuk menunaikan amanatnya". Jaminan disini bukan berbentuk tulisan atau saksi, melainkan kepercayaan dan amanah timbal balik. Utang diterima oleh debitur dan barang jaminan diberikan kepada kreditor. Mengacu pada tafsir di atas menjelaskan bahwa Islam tidak melarang orang yang memberikan pijaman untuk mendapatkan jaminan atas utang yang diberikan. Dalam prespektif perusahaan, aset tetap (tangible asset) yang dimiliki perusahaan dapat dijadikan jaminan yang diberikan kepada pihak kreditor bila dipandang perlu.

\section{Pengaruh Asset Maturity terhadap Debt Maturity Structure}

Variabel asset maturity

menunjukkan pengaruh positif signifikan terhadap struktur maturitas utang perusahaan (debt maturity structure). Hasil ini mengkonfirmasi penelitian yang dilakukan oleh Ozkan (2000), Hajiha (2012) dan Sukianto (2013). Hasil pada penelitian ini menunujukkan bahwa dalam pengambilan keputusan struktur maturitas utang perusahaan harus melakukan penyesuaian keputusan antara asset maturity perusahaan dengan debt maturity. Konsep pencocokan tersebut disebut dengan maturity matching. Pendekatan pencocokan waktu jatuh tempo merupakan suatu kebijakan keuangan yang mencocokan antara waktu jatuh tempo aset dan jatuh tempo kewajiban(Brigham,2011:266). Perusahaan dengan umur ekonomis aset yang panjang cenderung memiliki utang dengan jatuh tempo yang panjang pula. Sejalan dengan pernyataan tersebut, Hart Moore (1994) menjelaskan bahwa berdasarkan prinsip maturity matching perusahaan yang memiliki aset tetap dengan depresiasi yang lambat berimplikasi pada asset maturity yang lebih lama hal tersebut menyebabkan perusahaan akan menggunakan utang dengan jatuh tempo yang lebih lama pula. Jika perusahaan memiliki utang dengan jangka waktu yang lebih panjang dari jangka waktu asetnya, maka terdapat kecenderungan perusahaan tidak memiliki kas yang cukup untuk membayar utang pada saat jatuh tempo. Sebaliknya apabila perusahaan memiliki utang dengan jangka waktu yang lebih pendek dari jangka waktu asetnya maka perusahaan tersebut cenderung akan mengalami masalah likuiditas.

\section{Kesimpulan}

Berdasarkan hasil penelitian dan juga pembahasan pada bab sebelumnya, maka simpulan yang dapat diambil adalah:

1.Firm Size (Ukuran Perusahaan) berpengaruh positif signifikan secara parsial terhadap debt maturity structure sebesar 0.110905 dengan tingkat probabilitas 0.0081 . Nilai probabilitas lebih kecil dari tingkat signifikansi yang digunakan. Dengan demikian hipotesis pada penelitian ini terbukti karena $\mathrm{H}_{1}$ diterima dan $\mathrm{H}_{0}$ ditolak.

2.Profitability berpengaruh positif signifikan secara parsial terhadap debt maturity 
Islamy, et al/Jurnal Ekonomi Syariah Teori dan Terapan Vol. 5 No. 7 Juli 2018: 556-573; DETERMINAN DEBT MATURITY DEBT MATURITY PERUSAHAAN CONSUMER GOODS YANG TERDAFTAR DI ISSI

structure sebesar 0.487458 dengan tingkat probabilitas 0.0678 . Nilai probabilitas lebih kecil dari tingkat signifikansi yang digunakan. Dengan demikian hipotesis pada penelitian ini tidak terbukti karena $\mathrm{H}_{2}$ ditolak dan $\mathrm{H}_{0}$ diterima.

3.Tangibility berpengaruh negatif dan tidak signifikan secara parsial terhadap debt maturity structure sebesar -0.437155 dengan tingkat probabilitas 0.1042 . Nilai probabilitas lebih besar dari tingkat signifikansi yang digunakan. Dengan demikian hipotesis pada penelitian ini tidak terbukti karena $\mathrm{H}_{3}$ ditolak dan $\mathrm{H}_{0}$ diterima.

4.Asset maturity berpengaruh positif signifikan secara parsial terhadap debt maturity structure sebesar 0.00746 dengan tingkat probabilitas 0.0311 . Nilai probabilitas lebih kecil dari tingkat signifikansi yang digunakan dalam penelitian ini. Dengan demikian hipotesis pada penelitian ini terbukti karena $\mathrm{H}_{4}$ diterima dan $\mathrm{H}_{0}$ ditolak.

\section{Saran}

Adapun saran yang dapat digunakan untuk penelitian berikutnya adalah:

1.Mengingat firm size yang dicerminkan melalui total aktiva perusahaan, profitabilitas dan asset maturity memiliki pengaruh terhadap debt maturity structure, maka disarankan bagi pihak manajemen perusahaan dapat menentukan keputusan pendanaan yang tepat terkait dengan jatuh tempo utang yang sesuai bagi perusahaan.

2.Penelitian ini dapat dijadikan pertimbangan bagi investor dalam proses pembuatan keputusan untuk berinvesatsi pada suatu perusahaan yang berkaitan dengan risiko yang bersumber dari penggunaan utang.

3.Bagi calon kreditor firm Size, profitability, dan asset maturity dapat dijadikan pertimbangan untuk memberikan jatuh tempo utang yang tepat bagi perusahaan.

4. Penelitian selanjutnya dapat menambah lebih banyak sampel yaitu dari beberapa sektor perusahaan.

5.Penelitian ini membatasi pengamatan selama empat tahun yaitu tahun 20122015 maka dari itu untuk penelitian selanjutnya disarankan melakukan pengamatan dengan periode yang lebih lama agar dapat memberikan hasil penelitian yang lebih baik dan akurat. Selain itu, penambahan variabel lain juga disarankan agar bisa memberikan informasi yang lebih beragam, seperti business risk.

\section{Daftar Pustaka}

Anshori, M., \& Iswati. (2009). Buku Ajar Metodologi Penelitian. Surabaya: Airlangga University Press.

Barclay, \& Smith. (1995). The Maturity Structure of Corporate Debt. Journal of Finance, 50(2): 609-632.

Barnea. (1980). A Rationale for Debt Maturity Structure and Call Provisions in the Agency Theoritic Framework. Journal of Finance, 35(5):1233-1234.

Brigham, \& Houston, F. (2011). Dasar-Dasar Manajemen Keuangan. Jakarta: Salemba Empat.

Chiang, Y. (2014). Corporate Governance and The Dynamics of Capital Structure:New Evidence. Journal of Financial Intermediation . 
Islamy, et al/Jurnal Ekonomi Syariah Teori dan Terapan Vol. 5 No. 7 Juli 2018: 556-573; DETERMINAN DEBT MATURITY DEBT MATURITY PERUSAHAAN CONSUMER GOODS YANG TERDAFTAR DI ISSI

Ghozali, I. (2005). Aplikasi Analisis Multivariate dengan Progam SPSS. Semarang: Badan Penerbit Universitas Diponegoro.

Gujarati. (2013). Dasar-dasar Ekonometrika (Edisi Kelima ed.). Jakarta: Salemba Empat.

Hajiha, \& Akhlagi. (2012). The Determinants of Debt Maturity Structure in Iranian Firms. African Journal of Business Management, 1973-1982..

Huang, G. (2006). The Determinnats of Capital Structure: Evidence From China. China Economic Review, pp. 14-36.

Husnan, S., \& E, P. (2012). Dasar-dasar Manajemen Keuangan. Yogyakarta: UPP AMP YKN.

Jason, \& Hong, Z. (2006). The Financing Behaviour of Listed Chinese Firms. Accounting , 239-258.

Jensen, M., \& Wiliam. (1976). The Theory of Firm: Managerial Behaviour, Agency Cost and Ownership Structure. Journal of Financial Economic , 305-306.

Kasmir. (2013). Analisis Laporan Kevangan. Jakarta: Raja Grafindo Persada.

Leland, T. (1996). Optimal Capital Structur, Endogeneous Bankruptcy and Term Structure of Credit Spreads. Finance Journal , 987-1019.

Mai, M. (2006). Analisis Variabel-variabel yang Mempengaruhi Struktur Modal pada Perusahaanperusahaan LQ45 di Bursa Efek Jakarta. Tirtayasa Ekonometrika, 2, 228-245.

Modigliani, F., \& M., H. M. (1963). The Cost of Capital Corporatiom Finance and The Theory of Investment. American Economic Review, 261297.

Myers, S. C. (1977). Determinnats of Corporate Borrowings. Journal Of Financial Economics, 5, 147-175.

Modigliani, F., \& M., H. M. (1963). The Cost of Capital Corporatiom Finance and The Theory of Investment.
American Economic Review, 261297.

Ozkan. (2002). An Empirical of Corporate Debt Maturity Stucture. Europan Financial Management , 6(2):197212.

Pandey, I. M. (2001). Capital Structure and The Term Characteristics: Evidence From An Emerging Market. Journal of Financial , 1-17.

Rajan, G. R., \& Zingales. (1995). What Do We know Of Capital Structure? . Journal of Finance, 14121-14160.

Sajid, M. (2012). The Determinnats of Corporate Debt Maturity Structure. African Journal of Business Management, 6 (14), 4988-5003.

Shihab, Q. (2002). Tafsir Al Mishbah: Pesan, Kesan dan Keserasian Al- Qur'an. Ciputat: Lentera Hati.

Soekirman, A. (2015). Determinants of Debt Maturity in Indonesia Firm. IJABER, $13,5999-6016$.

Stephan, A. (2011). Corporate Debt Maturity Choice in Emerging Finacial Markets. The Quartly Review of Economics and Finance , $141-151$.

Stohs, M. H., \& Maurer. (1996). The Determinant of Corporate Debt Maturity Structure. Journal of Business, 69:279-312.

Sudana, I. M. (2011). Manajemen Keuangan Perusahaan. Surabaya: Erlangga.

Sukianto, A. (2013). Faktor- faktor yang Mempengaruhi Debt Maturity di Sektor Industri Manufaktur yang Terdaftar di Bursa Efek Indonesia Periode 2008-2012. Jurnal Ilmiag Mahasiswa Universitas Surabaya .

Terra, P. R. (2011). Determinants of Corporate Debt Maturity in Latin America. Europan Business Review, 23, 45-70.

Titman, S., \& Wessels, R. (1998). The Determinants of Capital Structure Choice. Journal of Finance, XLIII, 119. 
Islamy, et al/Jurnal Ekonomi Syariah Teori dan Terapan Vol. 5 No. 7 Juli 2018: 556-573; DETERMINAN DEBT MATURITY DEBT MATURITY PERUSAHAAN CONSUMER GOODS YANG TERDAFTAR DI ISSI

Weston, Z. F. (1997). Manajemen Keuangan (Edisi Kesembilan ed.). Jakarta: Binarupa Aksara.

Widiarjono, A. (2005). Ekonometrika: Teori dan Aplikasi untuk Ekonomi dan Bisnis. Yogyakarta: Ekonisia.

Zaini, Z. (2014). Memahami Bisnis Bank Syariah. Jakarta: PT. Gramedia Pustaka Utama. 